\title{
The Relative Roles of External Taurine Concentration and Medium Osmolality in the Regulation of Taurine Transport in LLC-PK1 and MDCK Cells
}

\author{
DEBORAH P. JONES, LESLIE A. MILLER, AND RUSSELL W. CHESNEY \\ Department of Pediatrics, University of Tennessee, Memphis, Le Bonheur Children's Medical Center, \\ Center for Pharmacokinetics and Therapeutics, Le Bonheur Children's Medical Center, Memphis,
}

Tennessee 38163

\begin{abstract}
Taurine is a $\beta$-sulfonic amino acid that serves as a nutrient
important for developing brain and retina and as an osmolyte in
the medullary collecting duct. The activity of the taurine trans-
port system is regulated by substrate supply and by the external
osmolality; these two stimuli induce changes in taurine transport.
Increased medium osmolality (500 mosmol) stimulates taurine
uptake into MDCK cells but not LLC-PK1 cells. The enhanced
taurine uptake that occurs in response to hyperosmolality is
localized primarily to the basolateral surface of MDCK cells,
whereas the adaptive response to medium taurine concentration
is expressed on both the apical and the basolateral surfaces of
both cell lines. The response of MDCK cells to medium osmo-
lality requires protein synthesis and RNA transcription and is
expressed in the presence of microtubular toxins. When cell
monolayers were loaded with taurine by incubation in high-
taurine medium before increasing medium osmolality, the ex-
pected increase in taurine uptake was blunted. Similarly, in-
creased external $\beta$-alanine (500 $\mu \mathrm{M}$ ) also prevented the
anticipated increase in taurine accumulation in response to hy-
pertonicity; aminoisobutyric acid and betaine (500 $\mu$ M) partially
prevented the increase in taurine transport after hypertonicity,
\end{abstract}
Taurine, a $\beta$-sulfonic amino acid that is found in millimolar intracellular concentrations in the kidney of many mammalian species, is postulated to have several key functions in the kidney; among these are the function of a nutritional substrate, as well as that of an osmolyte (1). Taurine is transported by the renal tubular cell by a sodium- and chloride-dependent transporter, which accepts the $\beta$-amino acid taurine and structural analogs such as $\beta$-alanine (2-5).

Received April 26, 1994; accepted September 20, 1994.

Correspondence and reprint requests: Deborah P. Jones, M.D., University of Tennessee, Memphis Department of Pediatrics, 956 Court Ave., Room B310, Memphis, TN 38163.

Supported in part by grants from the National Institutes of Health (DK 37223), The National Kidney Foundation of West Tennessee, LeBonheur Children's Medical Center, and The American Heart Association (91-004470, Clinician Scientist Award). whereas L-alanine had no effect. The concentration of taurine or structurally similar analogs in the external medium might modify the response of taurine accumulation after exposure to hypertonic medium, in that taurine-replete cells behave differently than taurine-depleted cells. These studies indicate that there are at least two distinct mechanisms involved in the regulation of taurine transport: external taurine concentration and medium osmolality, with taurine concentration seeming to be the predominant stimulus. Thus, the changes in cell taurine transport depend on the physiologic stimulus as well as the cell studied, a phenomenon that might be related to the renal tubular site of origin. (Pediatr Res 37: 227-232, 1995)
Abbreviations
GABA, aminoisobutyric acid
act $\mathrm{D}$, actinomycin $\mathrm{D}$
cyt $\mathrm{D}$, cytochalasin $\mathrm{D}$
Colch, colchicine
Cyclo, cyclohexamide
GPC, glycerophosphocholine
EBSS, Earle's balanced salt solution

The kidney taurine transporter serves at least two important functions: 1) to reabsorb filtered taurine as a nutrient (this occurs in the proximal tubule and has been shown to be functionally immature in the neonatal rat, to be regulated by dietary taurine intake, and to be abnormal in the hypertaurininuric mouse model) and 2) to offer protection to medullary collecting duct cells or to MDCK (Madin-Darby canine kidney) cells in response to increased external osmolality by serving as an osmolyte. In addition to sorbitol, inositol, glycerophosphorylcholine, and betaine, taurine is increased in the inner medulla of salt-loaded rats and MDCK cells. In the first example, taurine transporter activity changes in response to taurine supply, and in the latter, in response to external tonicity. We have been interested in contrasting the nature of the stimulus as well as the cell type: the proximal tubular cell, in 
which regulation of taurine transport by substrate concentration may be most important, in comparison with the collecting duct or distal cell, in which regulation by external osmolality is of greater importance to cell survival.

Taurine transport is regulated by the dietary intake of taurine in the rat (6), by the extracellular concentration in kidney cells in culture (7), and by medium osmolality in MDCK cells (8). We have previously demonstrated that taurine transport in both MDCK and LLC-PK1 cells is increased after incubation of cell monolayers in taurine-free medium and is decreased after incubation of cells in high levels of extracellular taurine (8). The adaptive response to medium taurine concentration was prevented when protein synthesis and protein export were inhibited (9). Inhibition of RNA transcription had no effect on the ability of the cells to respond to medium taurine concentration (9).

The following studies were performed to examine the interaction between medium hypertonicity and medium taurine concentration in regulation of taurine transport in cultured renal epithelial cells.

\section{METHODS}

Cell culture methods. LLC-PK1 and MDCK cell lines were obtained from American Type Culture Collection (Rockville, MD) and maintained in $5 \% \mathrm{CO}_{2}, 95 \%$ air. Standard medium, consisting of Dulbecco's modified Eagle's medium (1000 $\mathrm{mg} / \mathrm{L}$ glucose, $584 \mathrm{mg} / \mathrm{L}$ L-glutamine, and $110 \mathrm{mg} / \mathrm{L}$ sodium pyruvate) in a 1:1 mixture with Ham's F12 Nutrient Mixture (GIBCO/BRL, Life Technologies, Grand Island, NY), plus $10 \%$ FCS and penicillin $(100 \mathrm{U} / \mathrm{ml})$ and streptomycin $(100$ $\mu \mathrm{g} / \mathrm{mL}$ ), was used for routine cell carriage (7). Cells were subcultured by trypsinization and seeded onto $0.4-\mu \mathrm{m}$ polycarbonate filter supports (Costar, Cambridge, MA, Transwell) (10). For experiments, medium was replaced with a hormonally defined, serum-free formulation consisting of Dulbecco's modified Eagle's medium/F 12 with insulin $(5 \mu \mathrm{g} / \mathrm{mL})$, transferrin $(5 \mu \mathrm{g} / \mathrm{mL})$, prostaglandin $\mathrm{E} 1\left(2.5 \times 10^{-5} \mathrm{mg} / \mathrm{mL}\right)$, hydrocortisone $\left(5 \times 10^{-8} \mathrm{M}\right)$, and thyroxin $\left(5 \times 10^{-12} \mathrm{M}\right)$.

Transport studies. Uptake studies were performed on confluent monolayers 10-14 d after seeding. Briefly, cells were washed with EBSS at $37^{\circ} \mathrm{C}$. Uptake was initiated by the addition of EBSS with or without sodium, pH 7.4, with $50 \mu \mathrm{M}$ taurine $\left(0.5 \mu \mathrm{Ci}{ }^{3} \mathrm{H}\right.$-taurine) at $37^{\circ} \mathrm{C}(10)$. Uptake was terminated by the removal of uptake solution followed by three rapid washes with cold EBSS. The uptake solution contained ${ }^{14} \mathrm{C}$ inulin $(0.1 \mu \mathrm{Ci} / \mathrm{mL})$ in addition to ${ }^{3} \mathrm{H}$-taurine. Luminal uptake was measured by addition of uptake solution on the upper surface of the monolayer with an equal volume of EBSS on the lower chamber. For basolateral uptake, the uptake solution was added to the lower chamber and the EBSS with or without sodium to the upper chamber. The contralateral solution was sampled for contamination with ${ }^{14} \mathrm{C}$-inulin as a measure of monolayer integrity as well as contamination by the extracellular space. Monolayers were considered to be intact if the inulin leakage was less than $1 \%(10,11)$. Cells were solubilized in $1 \%$ SDS in $0.2 \mathrm{~N} \mathrm{NaOH}$. An aliquot was dispersed into Optifluor (Packard Instrument Co., Meriden, CT) and then radioactivity counted in a Packard Tricarb 2000-CA Liquid Scintillation Analyzer (Packard Instrument Co., Downers Grove, IL).

Total cell protein was measured by a modification of the Lowry method (12). Duplicate $10-\mu \mathrm{L}$ samples of cell homogenate and standards were pipetted into a 96-well microtiter plate. A $0.4-\mathrm{mL}$ volume of solution $\mathrm{A}$, consisting of $2 \%$ $\mathrm{Na}_{2} \mathrm{CO}_{3}, 1.0 \% \mathrm{CuSO}_{4}$, and $2.0 \% \mathrm{KNaC}_{4} \mathrm{H}_{4} \mathrm{O}_{6}(100: 1: 1)$ was added to each well, followed by $0.04 \mathrm{~mL}$ of $1.0 \mathrm{~N}$ FolinDiocalteau phenol reagent. After a 30-min incubation, the OD was measured using an automated microtiter plate spectrophotometer at a wavelength of 680 . The protein concentration of the samples were determined by linear regression analysis from standards of BSA. Uptake was then expressed as pmol of taurine per mg of cell protein per min.

Adaptive response to medium substrate concentration. Confluent cell monolayers were exposed for $24 \mathrm{~h}$ to hormonally defined, serum-free medium with 0,50 , or $500 \mu \mathrm{M}$ taurine. Uptake studies were performed after two $37^{\circ} \mathrm{C}$ washes in EBSS.

Response of cells to hypertonicity. Cell monolayers were exposed for $24 \mathrm{~h}$ to standard, hormonally defined, serum-free medium with $50 \mu \mathrm{M}$ taurine or with medium made hypertonic to 500 mosmol by the addition of raffinose. Monolayers were then gently washed twice in $37^{\circ} \mathrm{C}$ EBSS followed by measurement of taurine uptake in the presence and absence of sodium. MDCK monolayers were incubated in the presence of either act $\mathrm{D}(0.5 \mu \mathrm{g} / \mathrm{mL})(9,13)$, which inhibits RNA transcription; Cyclo $(70 \mu \mathrm{M})(9,13)$, which inhibits protein synthesis; and two inhibitors of microtubular depolymerization, cyt D (10 $\mu \mathrm{M})(14)$ and Colch $(50 \mu \mathrm{M})(9)$, for $2 \mathrm{~h}$ before and during a 12-h incubation in either standard or hypertonic medium.

Materials. Media, penicillin/streptomycin, trypsin, and FCS were purchased from GIBCO (Grand Island, NY). Radiolabeled taurine and inulin were purchased from New England Nuclear Corp. (Boston, MA). Insulin, hydrocortisone, thyroxin, prostaglandin E1, EBSS, choline chloride, choline bicarbonate, and other chemicals were from Sigma Chemical Co. (St. Louis, MO) and transferrin was from Calbiochem (La Jolla, CA).

Data analysis. Data comparisons were made by $t$ test for independent data and by analysis of variance with assistance from the computer program STATVIEW 512+ (Brainpower, Inc., Calabasas, CA).

\section{RESULTS}

Effect of hypertonicity and medium taurine concentration on taurine uptake in LLC-PK1 and MDCK cells. LLC-PK1 and MDCK cells were incubated for $24 \mathrm{~h}$ in either standard, serum-free, hormonally defined medium or in medium to which raffinose was added to achieve a final medium osmolality of 500 mosmol. In addition, the medium taurine concentration was varied so that the concentration of taurine was either 0,50 , or $500 \mu \mathrm{M}$. Taurine uptake was measured in the presence of sodium after the 24-h incubation (Fig. $1 A$ and $1 B$ ).

Taurine uptake by the apical surface of MDCK cells was unchanged after exposure to hypertonic medium when taurine was also present at 50 and $500 \mu \mathrm{M}$. Exposure of MDCK cell monolayers to hypertonic medium without taurine resulted in 

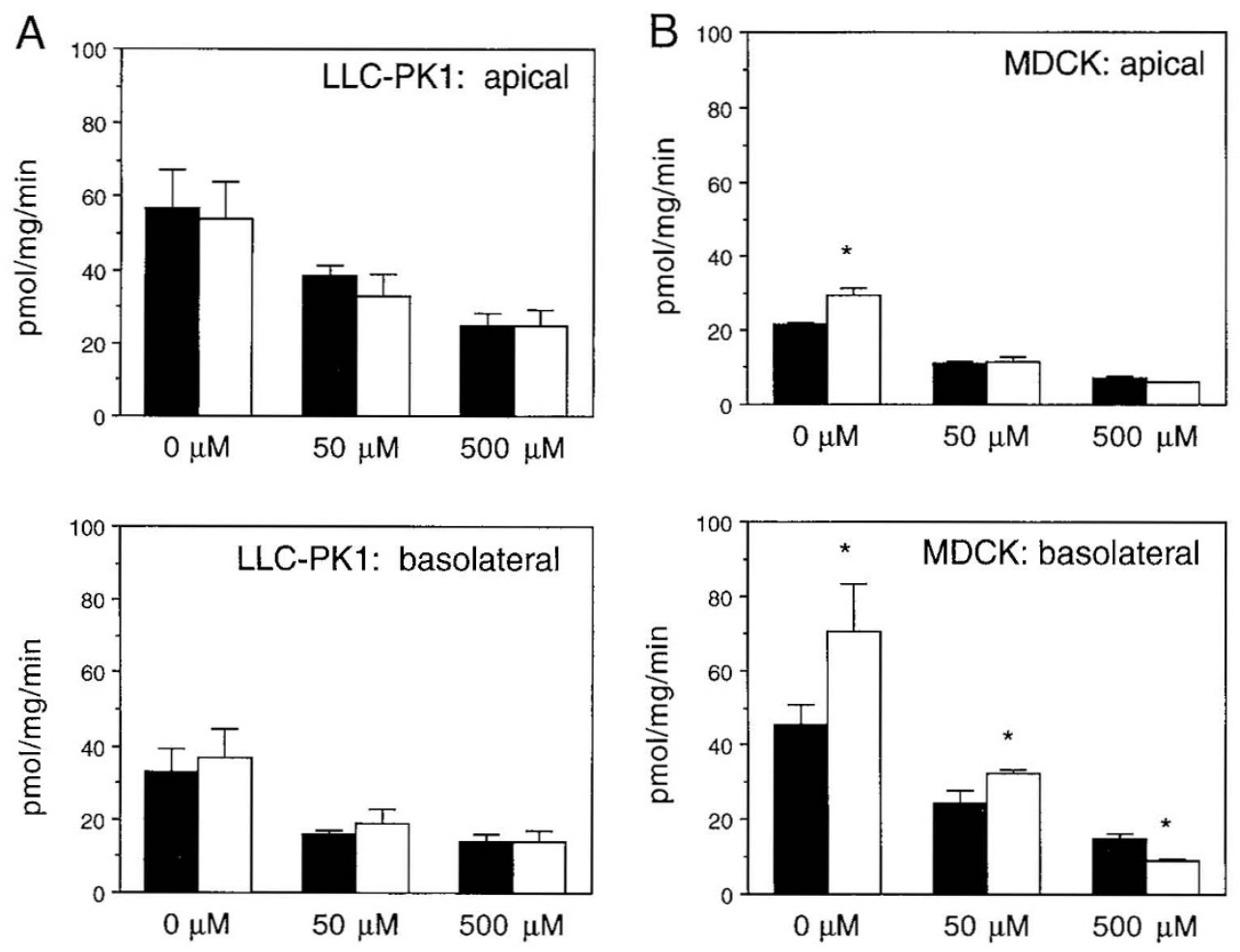

Figure 1. Polarity of taurine transport in LLC-PK1 $(A)$ and MDCK cells $(B)$ in response to variation in medium taurine concentration and medium tonicity. Confluent monolayers of LLC-PK1 and MDCK cells were incubated for $24 \mathrm{~h}$ in either standard osmolality, serum-free medium (black bars) or serum-free medium made hypertonic to 500 mosmol (open bars) by the addition of raffinose. To either medium was added no taurine $(0 \mu \mathrm{M})$ or 50 or $500 \mu \mathrm{M}$. Apical and basolateral taurine uptake was measured for $15 \mathrm{~min}$ in LLC-PK1 and assessed at $20 \mathrm{~min}$ in MDCK cells by incubation in uptake solution (EBSS, $50 \mu \mathrm{M}$ taurine). Values represent the mean \pm SEM of six filters. An asterisk indicates a $p$ value of $\leq 0.001$.

enhanced taurine uptake compared with control (Fig. 1B). Taurine accumulation by the basolateral surface of MDCK cells was increased after $24 \mathrm{~h}$ in hypertonic medium containing $50 \mu \mathrm{M}$ taurine or no taurine (Fig. $1 B$ ). Therefore, apical taurine accumulation by MDCK cells was not increased after increased medium osmolality, except when taurine was absent from the medium.

Conversely, taurine uptake by either the apical or the basolateral surface of LLC-PK1 cells was not different from controls after incubation in hypertonic medium (Fig. 1A); the adaptive response of cell monolayers to changes in medium taurine concentration was expressed by both surfaces of LLCPK1 cells, with relatively greater transporter activity on the apical surface compared with the basolateral surface, as was previously demonstrated (11). To summarize, taurine accumulation by either apical or basolateral surfaces of LLC-PK1 cells does not appear to be regulated by hypertonic external medium, regardless of the medium taurine concentration.

Time course of the response to hypertonicity in MDCK cells. Taurine uptake by the basolateral cell surface was measured at 2, 4, 8, 12, and $24 \mathrm{~h}$ after incubation of MDCK cells in hypertonic medium (Fig. 2). A significant increase in basolateral taurine accumulation was present by $4 \mathrm{~h}$ and was fully expressed by $12 \mathrm{~h}$ (Fig. 2). Therefore, the increase in taurine accumulation was observed within the initial $4 \mathrm{~h}$ after changing the medium and was maintained for a period of at least $24 \mathrm{~h}$.

Role of protein synthesis, RNA transcription, and microtubular function on adaptation to medium hypertonicity. Previous studies in LLC-PK1 cells demonstrated that the adap-

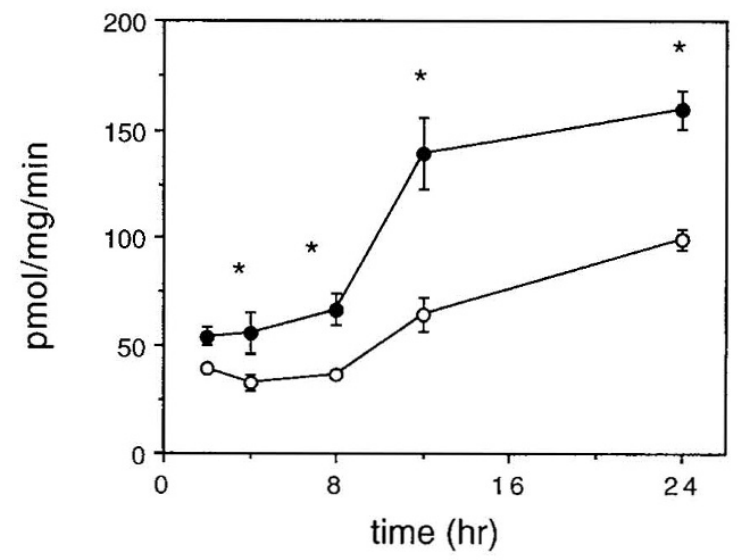

Figure 2. Time course of basolateral taurine uptake in MDCK cells after incubation in control (open circles) or hypertonic (black circles) medium. Taurine accumulation at $20 \mathrm{~min}$ (standard uptake buffer, $50 \mu \mathrm{M}$ taurine) was measured $2,4,8,12$, and $24 \mathrm{~h}$ after addition of hypertonic medium to both wells and compared with that in cells grown in isotonic medium. Values represent the mean \pm six filters. An asterisk indicates $p<.01$ by analysis of variance and then nonpaired $t$ test compared with the control.

tive response to changes in medium taurine concentration required intact microtubular apparatus as well as a functional protein-assembly mechanism. We examined whether RNA synthesis, protein translation, and an intact cytoskeleton were necessary for expression of the response to hypertonicity. MDCK monolayers were incubated in the presence of either act $\mathrm{D}(0.5 \mu \mathrm{g} / \mathrm{mL})$, which inhibits RNA transcription $(9,13)$; 
Cyclo $(70 \mu \mathrm{M})$, which inhibits protein synthesis $(9,13)$; or two inhibitors of microtubular depolymerization, cyt $\mathrm{D}(10 \mu \mathrm{M})$ (14), or Colch $(50 \mu \mathrm{M})(9)$, for $2 \mathrm{~h}$ before and during a 12-h incubation in either standard or hypertonic medium. Taurine accumulation by the basolateral cell surface was $95 \%$ of baseline (monolayers in isotonic medium) in the Cyclo-treated group and 103\% of baseline in the act D-treated group compared with an increase in taurine uptake of $161 \%$ of baseline in the control group (Fig. 3). Exposure to hypertonicity in the presence of cyt $\mathrm{D}$ and Colch increased taurine accumulation to $319 \%$ and $330 \%$ of baseline values, respectively (Fig. 3). To summarize, incubation in the presence of either Cyclo or act D prevented the adaptation of MDCK cells to hypertonicity, whereas incubation with cyt $\mathrm{D}$ or Colch did not prevent the observed increase in basolateral taurine accumulation. Thus, expression of the adaptive response to hypertonicity requires functions of RNA transcription and protein synthesis.

The importance of medium taurine concentration before exposure to hypertonic medium. We postulate that the primary stimulus for regulation of taurine transport is an intracellular taurine pool. To examine whether taurine availability would affect the response to hypertonicity in various taurine concentrations, MDCK cell monolayers were either taurine depleted (deprived) or taurine loaded for $24 \mathrm{~h}$ before manipulation of medium osmolality. The increase in taurine accumulation that occurs after exposure to hypertonicity was markedly blunted if cells had been previously loaded with taurine as compared with those incubated in the absence of taurine (Fig. $4 A$ ). In addition, taurine loading also prevented the expected increase in taurine accumulation after $24 \mathrm{~h}$ in the absence of medium taurine, irrespective of medium osmolality (Fig. $4 B$ ). As expected, uptake was lower in both groups exposed to $500 \mu \mathrm{M}$ taurine (Fig. 4B).

Effect of other osmolytes and amino acids on the ability of MDCK cells to respond to hypertonicity. To examine whether taurine decreases the response of MDCK cells to hypertonicity

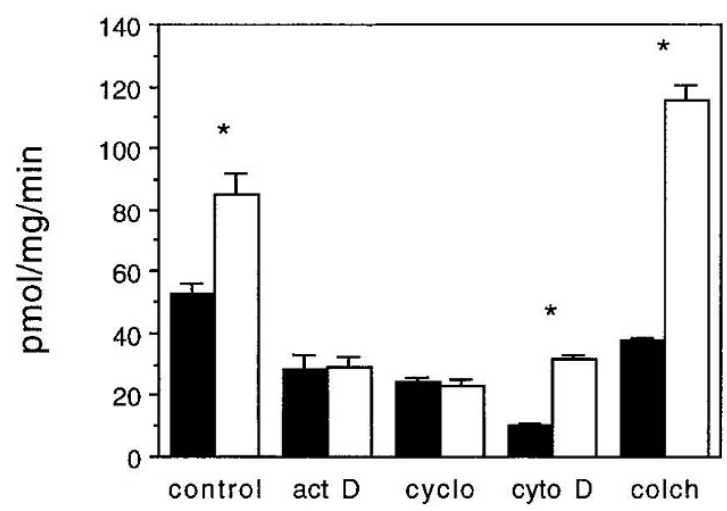

Figure 3. Effect of inhibitors on basolateral taurine uptake in MDCK cells. Confluent, filter-grown MDCK cells were incubated in the presence of one of the following: act $\mathrm{D}(0.5 \mu \mathrm{g} / \mathrm{mL})$, Cyclo (cyclo), $(70 \mu \mathrm{M})$, cyto $\mathrm{D}(10 \mu \mathrm{M})$, or Colch (colch) $(50 \mu \mathrm{M}) 2 \mathrm{~h}$ before and during a 12-h incubation in either isotonic (black bars) or hypertonic (open bars) serum-free medium containing $50 \mu \mathrm{M}$ taurine. After removal of medium, basolateral taurine accumulation was measured at $20 \mathrm{~min}$ (EBSS, $50 \mu \mathrm{M}$ taurine). Values represent the mean \pm SEM for four filters. An asterisk indicates statistical significance with $p \leq 0.5$ when the monolayers in hyperosmolar medium are compared with those in normotonic medium for each experimental group.
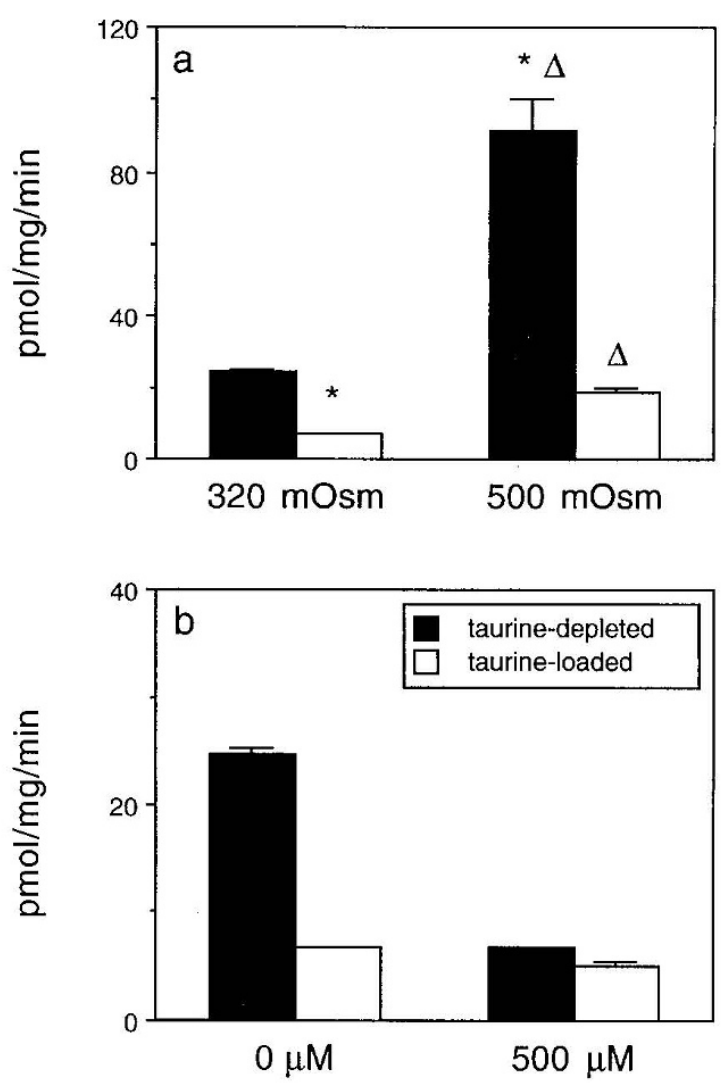

Figure 4. Effect of medium taurine concentration on the response of MDCK cells to hypertonic medium $(a)$ or changes in medium taurine concentration $(b)$. Confluent MDCK cells were either taurine depleted by incubation in isotonic, taurine-free medium for $24 \mathrm{~h}$ (black bars) or taurine loaded by incubation in isotonic medium containing $500 \mu \mathrm{M}$ taurine (open bars). After the first $24-\mathrm{h}$ incubation, medium was changed to either isotonic or hypertonic medium containing no taurine or $500 \mu \mathrm{M}$ taurine. Basolateral taurine uptake was measured at $20 \mathrm{~min}$ (EBSS, $50 \mu \mathrm{M}$ taurine). Values represent the mean \pm SEM for four filters. An asterisk denotes statistical significance $(p \leq 0.05)$ compared with the taurine-depleted, 320 mosmol group; $\Delta$ denoted statistical significance when compared with the taurine-loaded, 320 mosmol group.

because of its role as an osmolyte or as a substrate for the $\beta$-amino acid transporter, we incubated cells with another osmolyte, betaine, and a substrate which has been shown to share the betaine transporter, GABA, in addition to a structural analog of taurine, $\beta$-alanine, and a dissimilar compound, L-alanine. MDCK cells were incubated in the presence of standard, serum-free, hormonally defined medium containing $500 \mu \mathrm{M}$ taurine, GABA, betaine, L-alanine, or $\beta$-alanine for 24 $\mathrm{h}$; then bathing medium was changed to either standard or hypertonic medium with the same added amino acid for an additional $24 \mathrm{~h}$. Basolateral taurine accumulation was measured and compared with control ( $0 \mu \mathrm{M}$ taurine). The adaptive response of MDCK cells to hypertonicity was prevented by $\beta$-alanine but not by L-alanine (Fig. 5). In addition, both GABA and betaine prevented the increase in taurine accumulation after exposure to hypertonic medium, but not to the same degree as $\beta$-alanine. One might conclude that structural similarity and transporter homology are important in the ability of taurine to down-regulate the response of MDCK cells to high external osmolality; however, the presence of other osmolytes or similar compounds also causes down-regulation of taurine 


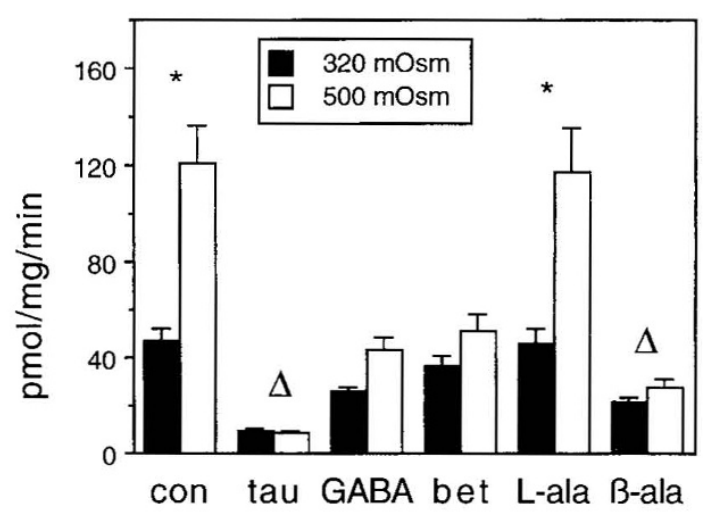

Figure 5. Effect of other solutes on the hypertonic adaptation of taurine transport in MDCK cells: MDCK cells were incubated for $24 \mathrm{~h}$ in either isotonic (black bars) or hypertonic medium (open bars) containing $500 \mu \mathrm{M}$ taurine, GABA, betaine, L-alanine, $\beta$-alanine, or no added amino acid. Values represent the mean \pm SEM of four filters. An asterisk represents statistical significance $(p \leq 0.05)$ when the $320 \mathrm{mosmol}$ and 500 mosmol values for each group are compared and $\Delta$ denotes statistical significance compared with the 320 mosmol control.

transport. Perhaps these compounds have an effect in the intracellular taurine pool and affect the expression of the taurine transporter in a similar fashion. These questions remain to be answered.

\section{DISCUSSION}

Increased medium osmolality (500 mosmol) stimulates taurine uptake into MDCK cells, a canine kidney cell line that originated from the distal tubule, most likely the collecting duct. LLC-PK1 cells, which are from the porcine proximal tubule, do not exhibit increased taurine accumulation after exposure to hypertonic medium. In contrast, both cell lines respond to changes in external taurine concentration with reciprocal changes in taurine accumulation (11). The enhanced taurine uptake that occurs in response to hyperosmolality is primarily localized to the basolateral surface of MDCK cells, whereas the adaptive response to medium taurine concentration is expressed on both the apical and the basolateral surfaces of LLC-PK1 and MDCK cell lines $(8,11)$. The response of taurine transporter activity to increased external medium tonicity is dissimilar in these two cultured renal epithelial cell lines and may be related to the renal tubular site of origin; however, one must be cautious in drawing conclusions about the intact renal tubule from data in continuous cell lines.

Although methylamines and polyols such as glycerophosphocholine and sorbitol are the major osmolytes accumulated by the renal medulla during antidiuresis, the adaptative accumulation of these osmolytes after exposure to hypertonicity is relatively slow (days); therefore, accumulation of amino acids such as taurine may play a more important role in the acute adaptation to high medium osmolality in the renal medulla, as has been demonstrated in the cerebral cortex $(15,16)$. In comparing the renal tubular handling of taurine and betaine, the accumulation of betaine is enhanced after long-term exposure of MDCK and PAP-HT25 cells (of papillary origin) to hyperosmolar medium $(17,18)$. In addition, the cellular content increased by $24 \mathrm{~h}$ in hypertonic medium and continued to increase over the next $5 \mathrm{~d}$ (19). Like taurine, betaine accumulation by MDCK cells is primarily localized to the basolateral surface (20). Kinetic analysis reveals the presence of two distinct transport systems for betaine, a high-affinity system and a low-affinity system (20). After exposure of MDCK cells to medium made hypertonic by the addition of $\mathrm{NaCl}$, the $\mathrm{V}_{\max }$ of both the low-affinity and the high-affinity systems is increased (20). The increased $V_{\max }$ was noted to peak at $24 \mathrm{~h}$ and then to decline if betaine was present in the medium, presumably after sufficient osmolyte was accumulated within the cell $(18,20)$. Uchida et al. $(8,21)$ reported that exposure of MDCK cells to medium made hypertonic by the addition of raffinose increases the $\mathrm{V}_{\max }$ for basolateral taurine uptake in MDCK cells, and this is accompanied by increased expression of a mRNA, which imparts taurine transporter activity when injected into Xenopus oocytes. Therefore, basolateral taurine transport and betaine transport increase when MDCK cells are exposed to a hypertonic environment.

Medium taurine concentration modifies the response of MDCK cells to hypertonic medium. As previously shown by others (8), incubation of MDCK cells in taurine-free medium further enhanced the adaptive response to hypertonicity, so that the two stimuli seemed additive. Our studies confirm their data. In addition, high medium taurine concentration in the face of hypertonicity blunts the enhanced basolateral uptake of taurine. One might speculate that in the presence of high medium taurine, adequate taurine is accumulated in the cell without the need to increase taurine transport. One stimulus for regulation of taurine transport, at least in response to medium taurine concentration or substrate supply, is the intracellular content of taurine. Uchida et al. (8) reported that cell taurine was unchanged in MDCK cells after incubation for $48 \mathrm{~h}$ in either isotonic or hypertonic taurine-free medium; however, the cellular taurine content was 2 -fold greater in monolayers incubated in hypertonic medium containing $50 \mu \mathrm{M}$ taurine compared with isotonic medium containing $50 \mu \mathrm{M}$ taurine. Cellular taurine content is probably not the only stimulus that increases taurine transport, because taurine accumulation by MDCK cells was enhanced after exposure to hypertonic medium, despite intracellular taurine levels that were comparable to control.

Medium taurine regulates taurine transport in LLC-PK1 cells by a mechanism that requires functional protein synthesis but not RNA transcription (9). In contrast, the response of MDCK cells to hypertonic medium is prevented by act $\mathrm{D}$, an inhibitor of RNA transcription, as well as cycloheximide, an inhibitor of protein synthesis. As previously noted, injection of mRNA from MDCK cells exposed to hypertonic medium into Xenopus oocytes has demonstrated increased taurine transporter activity caused by increased message. Thus, the mechanisms involved in increased taurine transport induced by changes in medium osmolality seem to be distinct from those involved in the response to changes in medium taurine concentration. RNA transcription is required for the osmolar response but not for the adaptive response to changes in substrate concentration.

Structural analogs of taurine such as $\beta$-alanine also blunted the adaptive response to hypertonic medium. Interestingly, the presence of $500 \mu \mathrm{M}$ GABA, which is not known to function as 
an osmolyte, blunted the response to hypertonic medium as well as reduced taurine uptake by the monolayers exposed to isotonic medium. GABA has been shown to competitively inhibit taurine uptake and has been proposed to be a potential substrate for the $\beta$-amino-acid transporter (2). In addition, GABA is postulated to be transported by the betaine transporter (8). Betaine also reduced the increase in taurine accumulation typically expressed after exposure to hypertonicity. The ability of betaine to alter taurine transport may be related to its known function as an osmolyte rather than as a substrate of the $\beta$-amino acid transport system. There may be regulatory mechanisms that enable one osmotically active substance to affect the accumulation of another.

Indeed, the presence of one osmolyte has been shown to alter the accumulation of another $(15,22)$. Renal medullary cells incubated in high extracellular osmolality (700 mosmol) in the presence of $0,0.5$, and $15 \mathrm{mM}$ betaine exhibit reciprocal changes in the cell sorbitol content and very small, yet significant, changes in cell GPC and inositol content $(15,22)$. This was not observed when inositol concentration was varied between 0 and $15 \mathrm{mM}$. In addition, the intracellular concentration of betaine increases when sorbitol is decreased; similarly, the accumulation of sorbitol is increased with low betaine $(15,22)$. Potential mechanisms by which the accumulation of one osmolyte can affect the accumulation of another include changes in the transport of the substrate, alterations in the availability of substrate for synthesis, and inhibition of enzymes involved in the synthesis of the osmolyte (22).

The accumulation of osmolytes has been studied in LLCPK1 and MDCK cell lines. After culture in high medium $\mathrm{NaCl}$, LLC-PK1 cells exhibit increased intracellular myo-inositol, betaine, and GPC with no change in intracellular sorbitol. MDCK cells accumulated myo-inositol, betaine, and GPC and did not accumulate sorbitol (18). Therefore, the accumulation of an amino acid or organic osmolyte may depend on intrinsic cell characteristics as well as the influence of other osmotically active agents in external medium or present within the cell.

The signal for the adaptive response to dietary taurine or external taurine concentration is most likely intracellular taurine concentration. The cell response seems to require intact protein synthesis as well as a functional cytoskeletal system, presumably to allow for synthesis and export of transporters that are targeted to the membrane. This constitutes the early response to alterations in taurine supply. A less rapid mechanism has been proposed to account for the most delayed response to dietary manipulation seen in the rat in which new message synthesis is likely to contribute (23). It seems likely that the mechanism by which elevated external tonicity increases taurine transport is different from that which responds to alterations in taurine supply. Addition of raffinose to the medium increases taurine transporter message expression in MDCK cells (8). This response may be modified if intracellular taurine is already increased. Thus, these two stimuli must interact. The mechanisms have yet to be elucidated; however, evidence exists for a protein kinase $\mathrm{C}$-dependent pathway in regulation of taurine transporter activity (9).

In conclusion, there are at least two distinct mechanisms involved in the regulation of taurine transport: external taurine and medium osmolality. The response to medium osmolality requires protein synthesis and RNA transcription and remains intact in the presence of microtubular toxins. The increase in taurine transport that occurs after increased external osmolality is expressed by the basolateral surface of MDCK cells but not by LLC-PK1 cells. The concentration of taurine in the external medium may modify the change in taurine uptake after hypertonic medium. That is, taurine-replete cells behave differently than taurine-depleted cells. In addition, taurine supply has a more generalized effect on taurine uptake in that it induces changes in accumulation by both surfaces of LLC-PK1 and MDCK cells. The adaptation that follows manipulation of taurine concentration does not seem to require RNA synthesis for expression, yet the adaptation is absent when protein synthesis or exocytosis is inhibited. Thus, the cell processes leading to changes in taurine transport at the membrane are divergent, depending on the physiologic stimulus as well as the cell studied.

\section{REFERENCES}

1. Huxtable RJ 1992 Physiological actions of taurine. Physiol Rev 72:101-163

2. Danzler WH, Silbernagl S 1976 Renal tubular reabsorption of taurine, $\gamma$-amino butyric acid (GABA) and $\beta$-alanine studied by continuous microperfusion. Pflugers Arch 367:123-128

3. Turner RJ $1986 \beta$-amino acid transport across the renal brush-border membrane is coupled to both $\mathrm{Na}^{+}$and $\mathrm{Cl}^{-}$. J Biol Chem 261:16060-16066

4. Wolff NA, Kinne R 1988 Taurine transport by rabbit kidney brush-border membranes: coupling to sodium, chloride, and the membrane potential. J Membr Biol 102:131-139

5. Zelikovic I, Stejskal-Lorenz E, Lohstroh P, Budreau A, Chesney RW 1989 Anion dependence of taurine transport by rat brush border membrane vesicles. Am J Physiol 256:F646-F655

6. Chesney RW, Gusowski N, Dabbaugh S 1985 Renal cortex taurine regulates the adaptive response to altered dietary intake of sulfur amino acids. J Clin Invest 76:2213-2221

7. Jones DP, Miller LA, Chesney RW 1990 Adaptive regulation of taurine transport in two continuous renal epithelial cell lines. Kidney Int 38:219-226

8. Uchida S, Kwon HM, Preston AS, Handler JS 1991 Taurine behaves as an osmolyte in MDCK cells: protection by polarized, regulated transport of taurine. J Clin Invest 88:656-662

9. Jones DP, Miller LA, Dowling C, Chesney RW 1991 Regulation of taurine transporter activity in LLC-PK1 cells: role of protein synthesis and protein kinase C activation. J Am Soc Nephrol 2:1021-1029

10. Boerner P, Evans-Layng M, Sang U-H 1986 Polarity of neutral amino acid transport and characterization of a broad specificity transport activity in a kidney epithelial cell line. J Biol Chem 261:13957-13962

11. Jones DP, Miller LA, Chesney RW 1993 Polarity of taurine transport in cultured renal epithelial cell lines: LLC-PK1 and MDCK. Am J Physiol 265:F137-F145

12. Lowry OH, Rosebrough NJ, Farr AL, Randall RJ 1951 Protein measurement with the Folin phenol reagent. J Biol Chem 193:265-275

13. Biber J, Forgo J, Murer H 1988 Modulation of Na-Pi cotransport in opossum kidney cells by extracellular phosphate. Am J Physiol 255:C155-C161

14. McIntosh RP, McIntosh JEA, Starling L 1987 Effects of modifiers of cytoskeletal structures on the dynamics of release of LH from sheep anterior pituitary cells stimulated with gonadotrophin-releasing hormone, $\mathrm{K}^{+}$or phorbol ester. J Endocrinol 112:289-298

15. Garcia-Perez A, Burg MB 1991 Renal medullary organic osmolytes. Physiol Rev 71:1081-1115

16. Law RO1991 Amino acids as volume regulatory osmolytes in mammalian cells. Comp Biochem Physiol A 99:263-277

17. Heilig CW, Brenner RM, Yu ASL, Kine BC, Gullans SR 1990 Modulation of osmolytes in MDCK cells by solutes, inhibitors and vasopressin. Am J Physiol 259:F653-F659

18. Nakanishi T, Turner RJ, Burg MB 1990 Osmoregulation of betaine transport in mammalian renal medullary cells. Am J Physiol 258:F1061-F1067

19. Nakanishi T, Balaban RS, Burg MB 1988 Survey of osmolytes in renal cell lines. Am J Physiol 255:C181-C191

20. Yamamauchi A, Kwon HM, Uchida S, Preston AS, Handler JS 1991 Myo-inositol and betaine transporters regulated by tonicity are basolateral in MDCK cells. Am J Physiol 261:F197-F202

21. Uchida S, Nakanishi T, Kwon HM, Preston A, Handler JS 1991 Expression of MDCK cell $\mathrm{Na}$ and $\mathrm{Cl}$ dependent taurine transporter in Xenopus laevis oocytes. J Biol Chem 266:9605-9609

22. Moriyama T, Garcia-Perez A, Burg MB 1990 Factors affecting the ratio of different organic osmolytes in renal medullary cells. Am J Physiol 259:F847--F858

23. Han X, Chesney RW 1993 Developmental expression of rat kidney taurine transporter and its regulation by diet in Xenopus laevis oocytes. J Am Soc Nephrol 3:114 